\title{
EMPOWERING LEADERSHIP DAN KINERJA PEGAWAI: SEBUAH STUDI EMPIRIS PADA DISTRIK $X$ KABUPATEN MAYBRAT
}

\author{
Reijeng Tabara $^{1}$, Niar Azriya ${ }^{2}$, Uswatul Mardliyah ${ }^{3}$ \\ Universitas Nani Bili Nusantara ${ }^{1}$, Universitas Sang Bumi Jurai ${ }^{2}$, Universitas \\ Muhammadiyah Sorong ${ }^{3}$ \\ regentabara@gmail.com ${ }^{1}$, niaraziya@gmail.com ${ }^{2}$
}

\begin{abstract}
Abstrak
Tujuan dari penelitian ini adalah untuk mengetahui pengaruh empowering leadership terhadap kinerja Pegawai Distrik X kabupaten Maybrat. Penelitian ini menggunakan metode explanatory research dengan Teknik purposive sampling. Analisis data menggunakan structural equation modeling (SEM) dengan metode analisis yaitu Partial Least Square (PLS) untuk menganalisis 45 pegawai. Pengolahan data menggunakan Software Smart PLS 2.0M3. Hasil penelitian menunjukkan terdapat pengaruh positif dan signifikan antara empowering leadership terhadap kinerja Pegawai. Hasil studi ini mengindikasikan bahwa semakin tinggi empowering leadership yang dimiliki organisasi, maka akan semakin meningkatkan kinerja Pegawai pada Distrik X kabupaten Maybrat Papua Barat.
\end{abstract}

Kata kunci: empowering leadership dan Kinerja Pegawai

\begin{abstract}
Abstract. The purpose of this study was to determine the effect of empowering leadership on the performance of District $X$ employees, Maybrat district. This research uses explanatory research method with purposive sampling technique. Data analysis used structural equation modeling (SEM) with the analytical method of Partial Least Square (PLS) to analyze 45 employees. Data processing using Smart PLS 2.0M3 Software. The results showed that there was a positive and significant influence between empowering leadership on employee performance. The results of this study indicate that the higher the empowering leadership the organization has, the higher the performance of employees in District X, Maybrat district, West Papua.
\end{abstract}

Keywords: empowering leadership and Employee Performance

\section{PENDAHULUAN}

Pandemi Covid-19 dan perlambatan ekonomi yang terjadi dewasa ini membuat organisasi dipaksa untuk bersaing dalam ketidakpastian lingkungan yang kompleks. Selain itu, dengan tingkat kompleksitas lingkungan yang tinggi, organisasi dituntut melakukan perubahan yang cepat agar tetap unggul dalam kompetisi (Farid et al., 2020; Pankajakshan, 2011; Tabara, 2018). Sebelum mengadopsi perubahan yang terjadi dan tetap unggul dalam melakukan kompetisi, menjadi semakin penting bagi organisasi untuk memastikan memiliki tenaga kerja superior dan berkembang di pasar yang serba cepat dan kompetitif (Dlamani et al., 2018; Dwina Kuswadani, Dhami Johar Damiri, 2020; Vu, 2020). Dalam proses perubahan organisasi formal maupun non formal selalu juga diperlukan kesiapan individu untuk berubah (Ali et al., 2018). van Assen, (2020) ; van Knippenberg et al., (2021) menjelaskan Aspek leader dapat mempengaruhi kesiapan individu untuk berubah dan dapat ditingkatkan jika ada peran pemimpin yang mampu sebagai agent of change serta mampu 
mentransformasikan perubahan organisasi ke arah yang lebih baik.

Dalam perkembangan sebuah organisasi, kontruks empowering leadership saat ini juga banyak dikaji dalam aspek perilaku pemimpin untuk mendelegasikan kewenangan yang dimiliki (Kearney et al., 2019; Sarwat et al., 2011; van Assen, 2020). Tidak lagi mempertahankan kekuatan berdasarkan kewenangan yang dimiliki, empowering leadership terkini justru dikaji sebagai perilaku untuk membagi kewenangan pada pihak yang dipimpin. Konsep empowering leadership saat ini justru dipandang efektif pada era ini untuk mendapatkan kekuatan memimpin (Jung et al., 2020). Delegasi kewenangan membuat pihak yang dipimpin memiliki daya lebih untuk mengambil keputusan sesuai lingkup tugasnya (Widianto, 2021). Proses pengambilan keputusan menjadi terdesentrasilisasi dan spesifik sesuai kewenangan masing-masing pihak. Dalam kondisi ini pemimpin hadir untuk mengkonsentrasikan berbagai keputusan yang diambil dari pihak-pihak yang telah mendapatkan delegasi tersebut (Webber et al., 2020).

Beberapa penelitian telah melaporkan bahwa empowering leadership memainkan peran penting untuk mencapai tujuan organisasi dan mendorong pengembangan perilaku inovatif karyawan dan pekerjaan lainnya (Cheong et al., 2016; Ghadi \& Almanaga'h, 2020; Jung et al., 2020; Tian \& Zhang, 2020; Webber et al., 2020). Penelitian sebelumnya yang meneliti hubungan antara empowering leadership dan kinerja pegawai lebih berfokus pada organisasi di Amerika Utara daripada di Asia. Selain itu, beberapa penelitian telah meneliti hubungan ini dalam situasi zona publik di Asia (Cheong et al., 2016; Ghadi \& Almanaga'h, 2020; Jung et al., 2020; Kundu et al., 2019; Lee et al., 2017), tetapi tidak memiliki sorotan untuk sektor publik Indonesia khususnya wilayah Papua Barat.

\section{Rumusan Masalah}

Berdasarkan uraian latar belakang masalah diatas, rumusan masalah dalam penelitian ini adalah bagaimanakah pengaruh empowering leadership terhadap kinerja pegawai pada Distrik X Kabupaten Maybrat?

\section{Tujuan Penelitian}

Berdasarkan Rumusan Masalah, maka tujuan dari Penelitian ini adalah untuk menganalisis pengaruh empowering leadership terhadap kinerja pegawai pada Distrik X Kabupaten Maybrat.

\section{TINJAUAN TEORITIS}

\section{Kinerja Pegawai}

Menurut Waris, (2015), kinerja adalah merupakan totalitas hasil kerja yang dicapai seseorang dalam melaksanakan tugastugasnya atas kecakapan, usaha dan kesempatan dari pimpinannya. Berdasarkan paparan diatas kinerja adalah suatu hasil yang dicapai seseorang dalam melaksanakan tugas-tugas yang didasarkan atas kecakapan, pengalaman dan kesungguhan serta waktu menurut standar dan kriteria yang telah ditetapkan sebelumnya.

Mangkunegara, (2012) dan Waris, (2015) menjelaskan pengukuran kinerja menggunakan aspek sebagai berikut :

1. Kualitas kerja adalah seberapa baik seorang karyawan mengerjakan apa yang seharusnya dikerjakan.

2. Kuantitas kerja adalah seberapa lama seorang pegawai bekerja dalam satu harinya. Kuantitas kerja ini dapat dilihat dari kecepatan kerja setiap pegawai itu masing-masing.

3. Pelaksanaan tugas adalah seberapa jauh karyawan mampu melakukan pekerjaannya dengan akurat atau tidak ada kesalahan.

4. Tanggung jawab terhadap pekerjaan adalah kesadaran akan kewajiban karyawan untuk melakukan pekerjaan yang diberikan oleh perusahaan/instansi. 


\section{Empowering Leadership}

empowering leadership merupakan proses keterwakilan kekuasaan, serta mengalirkan otonomi dan tanggung jawab kepada pengikut, tim, atau kolektif lewat serangkaian perilaku pemimpin khusus bagi pegawai untuk meningkatkan motivasi internal dan menggapai keberhasilan kerja (Byun, 2016; Tian \& Zhang, 2020). Sönmez Çakir \& Adigüzel, (2020) menambahkan empowering leadership sebuah perilaku seorang pemimpin yang dapat merasakan dan memberikan motivasi atau tingkah laku pegawai, yang mana menunjukkan seorang pemimpin memiliki sikap tertarik dan peduli akan pegawainya, dapat berkomunikasi secara efektif, serta dapat memberikan inspirasi kepada pegawainya. Indikator empowering leadership adalah sebagai berikut (Amundsen \& Martinsen, 2014):

1. Menghargai karyawan (Respect) Pemimpin percaya akan kemampuan karyawannya serta bersedia mendengarkan pendapat yang disampaikan oleh karyawannya.

2. Mengembangkan karyawan (Development) Pemimpin dapat menjadi teladan bagi karyawan serta memberikan kesempatan bagi karyawannya untuk terus belajar dalam mengambil keputusan.

3. Membangun komunitas (Community) Pemimpin dapat menciptakan hubungan kerja yang menyenangkan, seiring dengan kepedulian serta komunikasi yang baik antara satu dengan yang lain.

4. Pendelegasian kekuasaan (Delegation) Pemimpin dapat mendelegasikan tugas dan tanggung jawab dengan jelas untuk mencapai goal yang telah ditetapkan.

\section{METODE PENELITIAN}

Jenis Penelitian menggunakan metode explanatary research. Sumber data menggunakan data primer yang diperoleh berdasarkan kuesioner yang dibagikan kepada responden yang berisi tanggapan responden terhadap variabel penelitian. Populasi dalam penelitian adalah seluruh pegawai yang bekerja pada distric $X$ kabupaten maybrat. Teknik pengambilan sampel penelitian menggunakan metode purposive sampling dengan mengacu pada pertimbangan tertentu menurut Sugiyono, (2018). Oleh karena itu, mengacu pada pendapat tersebut maka jumlah sampel penelitian sebanyak 45 pegawai yang terdistribusi pada Distrik X kabupaten Maybrat.

Total kuesioner terdiri dari 8 item. Seluruh item diukur menggunakan skala Likert dengan 5 titik skala di mana $1=$ sangat tidak setuju dan $5=$ sangat setuju. Variabel kinerja pegawai dalam penelitian ini diukur melalui empat indikator yaitu kualitas kerja, kuantitas kerja, pelaksanaan kerja, dan tanggungjawab (Robbins \& Judge, 2009; Waris, 2015). Variabel empowering leadership diukur melalui empat indikator yaitu respect, development, Community, dan Delegation (Amundsen \& Martinsen, 2014). Selanjutnya Teknik analisis data menggunakan Structural Equation Model (SEM). Teknik SEM digunakan untuk memeriksa dan membenarkan suatu model. Model-model yang dimaksud adalah analisis regresi, analisis Jalur (Path Analysis), dan analisis konfirmatori (Confirmatory Factor analysis). Program yang dipakai dalam penelitian ini adalah Smart PLS 2.0M3 (Hair, J. F.; Black, W. C.; Babin, B. J.; Anderson, 2014; Ringle et al., 2005)

\section{HASIL DAN PEMBAHASAN}

\section{Karakteristik Responden}

Berdasarkan data hasil penelitian yang telah dikumpulkan melalui kuesioner yang berjumlah 45 responden maka diperoleh karakteristik responden sebagai berikut: 


\section{EKOMBIS Sains}

Table 1. Karakteristik Responden

\begin{tabular}{llll}
\hline Keterangan & Frekuensi & Persentase & Total \\
\hline Jenis Kelamin & & & 45 \\
Laki_laki & 20 & $44 \%$ & \\
Perempuan & 25 & $56 \%$ & \\
& & & \\
Umur & & & 45 \\
$20-30$ tahun & 15 & $33 \%$ & \\
$31-40$ tahun & 26 & $58 \%$ & \\
$>41$ tahun & 4 & $9 \%$ & \\
& & & \\
Lama Kerja & & & 45 \\
$<5$ tahun & 29 & $64 \%$ & \\
$>5$ tahun & 16 & $36 \%$ & \\
& & & \\
Tingkat & & & \\
Pendidikan & & & \\
SMA & 8 & $18 \%$ & \\
DIII & 11 & $24 \%$ & \\
S1 & 26 & $58 \%$ & \\
\multicolumn{1}{c}{ Sumber : Data Primer diolah. 2020}
\end{tabular}

Tabel 1 menjelaskan dari 45 responden 56\% adalah perempuan dan $44 \%$ adalah laki-laki, selain itu umumnya responden didominasi oleh usia 31-40tahun (58\%), 20-30 tahun (33\%) dan >41 tahun (9\%). Sehubungan dengan lama kerja responden sebanyak $64 \%$ $<5$ tahun dan sebanyak $16 \%>5$ tahun. Sehubungan dengan tingkat pendidikan responden S1 sebanyak 58\%, 24\% lulus DIII , dan sebanyak $18 \%$ lulus SMA.

\section{Hasil analisis PLS}

Analisis Outer model loading factor or Path Coefficient Test:

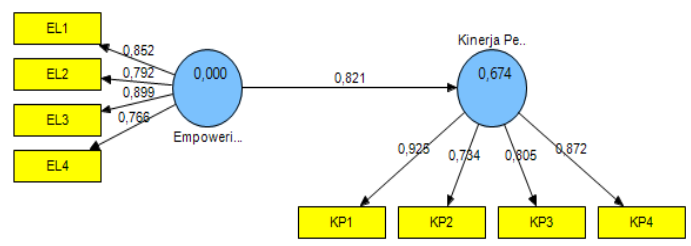

Hasil Outer Model Berdasarkan uji convergent validity, diketahui bahwa Convergent Validity dari indikator empowering leadership, dan Kinerja Pegawai memiliki nilai outer loading $>0,5$ dengan demikian semua indikator variabel adalah valid
Tabel 2. Convergent validity Variabel Penelitian

\begin{tabular}{ccc}
\hline & $\begin{array}{c}\text { Empowering } \\
\text { Leadership }\end{array}$ & $\begin{array}{c}\text { Kinerja } \\
\text { Pegawai }\end{array}$ \\
\hline EL1 & 0,851690 & \\
EL2 & 0,791820 & \\
EL3 & 0,898798 & \\
EL4 & 0,766102 & \\
KP1 & & 0,924992 \\
KP2 & & 0,733982 \\
KP3 & & 0,804897 \\
KP4 & & 0,871815 \\
\hline
\end{tabular}

Source: Data Primer diolah, 2021

Dari hasil output SmartPLS, semua konstruk memiliki nilai composite reliability di atas 0,7. Jadi dapat disimpulkan bahwa seluruh variabel penelitian adalah reliabel. Berikut tabel nilai composite reliability

Tabel 3. Composite Reliability

\begin{tabular}{lc}
\hline & Composite Reliability \\
\hline $\begin{array}{l}\text { empowering } \\
\text { leadership }\end{array}$ & 0,897291 \\
Kinerja Pegawai & 0,902817
\end{tabular}

Source: Data Primer diolah, 2021

Hasil Inner Model. Menilai inner model adalah melihat hubungan antara konstruk laten dengan melihat hasil estimasi koefisien parameter path dan tingkat signifikansinya (Ghozali, 2011). Dasar yang digunakan dalam menguji hipotesis adalah nilai yang terdapat pada output result for inner weight seperti terlihat pada tabel 4 berikut ini : 
Tabel 4. Result for inner weight

\begin{tabular}{cccccc}
\hline & $\begin{array}{c}\text { Original } \\
\text { Sample (O) }\end{array}$ & $\begin{array}{c}\text { Sample Mean } \\
(\mathbf{M})\end{array}$ & $\begin{array}{c}\text { Standar } \\
\text { Deviation } \\
\text { (STDEV) }\end{array}$ & $\begin{array}{c}\text { Standar Error } \\
\text { ( STERR) }\end{array}$ & $\begin{array}{c}\text { T Statistics } \\
\text { (IO/STERR) }\end{array}$ \\
\hline $\begin{array}{c}\text { Empowering } \\
\text { Leadership -> } \\
\text { Kinerja } \\
\text { Pegawai }\end{array}$ & 0,820737 & 0,828936 & 0,025897 & 0,025897 & 31,692956 \\
& & & & & \\
\hline
\end{tabular}

Source: Data Primer diolah, 2021

empowering leadership berpengaruh signifikan terhadap kinerja pegawai. Hal ini dibuktikan dengan nilai koefisien parameter 0.820 dan signifikan t-statistik $31.692>\mathrm{t}$ tabel 1,679. Dengan demikian hipotesis 1 yang menyatakan empowering leadership berpengaruh signifikan terhadap kinerja pegawai diterima.

\section{Pembahasan.}

Empowering leadership berpengaruh signifikan terhadap kinerja pegawai. Hal ini sesuai dengan penelitian yang telah dilakukan oleh Kundu et al., (2019) dan I. Wong Humborstad et al., (2014) empowering leadership juga gaya kepemimpinan yang menginspirasi bawahannya untuk selalu meningkatkan kinerja organisasi dan pegawai. Temuan ini sejalan dengan teori $\mathrm{Vu},(2020)$; Bunyamin et al., (2013); Kim et al., (2018); dan Kim \& Beehr, (2020) yang menyatakan bahwa empowering leadership adalah gaya kepemimpinan yang menargetkan pengikut untuk mengembangkan kontrol diri mereka sendiri, pegawai didorong untuk berpartisipasi dalam pengambilan keputusan, dan mereka diarahkan untuk berinovasi sendiri. Saat individu merasa bahwa dirinya diberikan kepercayaan, berpartisipasi dalam pengambilan keputusan, dan diberikan dukungan dan dorongan, maka mereka akan merasa lebih giat dalam berkinerja, sehingga Kinerja pegawai dapat tercapai. Hasil empiris di lapangan juga menunjukkan bahwa besarnya empowering leadership dapat menciptakan suasana kerja yang kondusif, karena pemimpin senantiasa memberikan arahan yang bersifat membangun karakter individu, memberikan kesempatan untuk pengambilan keputusan yang partisipatif, pembinaan, serta menunjukkan kepedulian terhadap masing-masing pegawai yang tujuan utamanya untuk meningkatkan kinerja pegawai.

Meningkatkan empowering leadership dan kinerja pegawai sangatlah efektif untuk diaplikasikan pada berbagai tipe pekerjaan organisasi. Kajian literatur pada berbagai penelitian, empowering leadership dapat digunakan dalam manajemen kinerja. Bahkan penelitian yang dilakukan menyatakan bahwa empowering leadership efektif mempunyai kontribusi dalam meningkatkan kinerja pegawai di Distrik X Kabupaten Maybrat Papua Barat. Wewenang yang diberikan oleh pemimpin turut meningkatkan rasa dipercaya pegawai sehingga mereka mau berkinerja lebih untuk meningkatkan kinerja.

\section{PENUTUP}

\section{Kesimpulan}

Penelitian ini dilakukan untuk mengetahui keterkaitan pengaruh antarvariabel pada empowering leadership dan kinerja pegawai pada kantor Distrik X kabupaten Maybrat Papua Barat. Secara keseluruhan Hasil penelitian ini menjelaskan bahwa empowering leadership berpengaruh positif dan signifikan terhadap kinerja pegawai. Artinya, semakin tinggi empowering leaderhip dalam organisasi, maka variabel tersebut akan mempengaruhi peningkatan 


\section{EKOMBIS Sains}

kinerja pegawai. Tentunya hasil penelitian ini memberikan kontribusi dasar teoritis manajemen kepemimpinan.

\section{Saran}

Seperti kebanyakan studi sebelumnya, penelitian ini memiliki keterbatasan yang harus diperhatikan, terkait dengan generalisasi penelitian. Teknik pengumpulan data yang menggunakan kuesioner belum cukup untuk mengukur konstruk empowering leadership Demikian pula wilayah objek penelitian yang hanya lingkup distrik perlu dipertimbangkan untuk memperoleh hasil penelitian yang lebih baik lagi. Walaupun penelitian ini menunjukkan relevansi empowering leadership terhadap kinerja pegawai, penelitian ini juga tidak memperhitungkan sejumlah variabel lain yang dapat memengaruhi hasil yang dilaporkan. Oleh karena itu, studi di masa depan harus menggunakan desain eksperimental dan longitudinal untuk menetapkan kesimpulan lebih lanjut tentang arah Kausalitas.

\section{DAFTAR PUSTAKA}

[1] Ali, M., Lei, S., SHi-Jie, Z., \& Rahman, M. A. (2018). empowering leadership and employee performance: A mediating role of thriving at work. International Journal of Asian Business and Information Management, 9(2). https://doi.org/10.4018/IJABIM.20180 40101

[2] Amundsen, S., \& Martinsen, O. L. (2014). Self-other agreement in empowering leadership :

Relationships with leader effectiveness and subordinates' job satisfaction and turnover intention. Leadership Quarterly, 25(4). https://doi.org/10.1016/j.leaqua.2014.0 4.007
[3] Bunyamin, Z., Efendi, R., Andayani, N. N., Penelitian, B., \& Serealia, T. (2013). Pemanfaatan Limbah Jagung untuk Industri Pakan Ternak. Seminar Nasional Inovasi Teknologi Pertanian.

[4] Byun, G. (2016). The antecedents and consequences of empowering leadership : A test of trickle-down effects. In ProQuest Dissertations and Theses.

[5] Cheong, M., Spain, S. M., Yammarino, F. J., \& Yun, S. (2016). Two faces of empowering leadership : Enabling and burdening. Leadership Quarterly, $27(4)$

https://doi.org/10.1016/j.leaqua.2016.0 1.006

[6] Dlamani, P., Zhou, I., \& Mokua, J. K. (2018). Supervisor Workplace Gossip and Employee Job Performance: The Mediation Effect of Employee Job Engagement. International Journal of Research in Business and Social Science (2147-4478), 7(4). https://doi.org/10.20525/ijrbs.v7i4.886

[7] Dwina Kuswadani, Dhami Johar Damiri, E. (2020). TRANSFORMASI SUMBER DAYA MANUSIA MENGHADAPI PASAR TENAGA KERJA ERA REVOLUSI INDUSTRI 4.0. KREATIF : Jurnal Ilmiah Prodi Manajemen Universitas Pamulang, $8(1)$.

https://doi.org/10.32493/jk.v8i1.y2020 .p91-103

[8] Farid, F., Rahman, A., Raehani, C., \& Febrianti, D. (2020). Dinamika

Kekuasaan dalam Perubahan Organisasi. Jurnal Sinar Manajemen, 7(2).

[9] Ghadi, M. Y., \& Almanaga'h, K. S. (2020). The role of job crafting in the relationship between empowering leadership and happiness at work: An empirical analysis. Business: Theory and Practice, 21(1). https://doi.org/10.3846/btp.2020.1110 
9

[10] Ghozali, I. (2011). Moderated Structural Equation Modeling. In Model persamaan struktural. Konsep dan aplikasi dengan program AMOS 19.0.

[11] Hair, J. F.; Black, W. C.; Babin, B. J.; Anderson, R. E. (2014). Multivariate Data Analysis. In Statistica Neerlandica. https://doi.org/10.1111/j.14679574.1962.tb01184.x

[12] I. Wong Humborstad, S., G.L. Nerstad, C., \& Dysvik, A. (2014). empowering leadership , employee goal orientations and work performance. Personnel Review, 43(2). https://doi.org/10.1108/pr-01-20120008

[13] Jung, K. B., Kang, S. W., \& Choi, S. B. (2020). empowering leadership , risk-taking behavior, and employees' commitment to organizational change: The mediated moderating role of task complexity. Sustainability (Switzerland), 12(6). https://doi.org/10.3390/su12062340

[14] Kearney, E., Shemla, M., van Knippenberg, D., \& Scholz, F. A. (2019). A paradox perspective on the interactive effects of visionary and empowering leadership . Organizational Behavior and Human Decision Processes, 155. https://doi.org/10.1016/j.obhdp.2019.0 1.001

[15] Kim, M., \& Beehr, T. A. (2020). empowering leadership : leading people to be present through affective organizational commitment?*. International Journal of Human Resource Management, 31(16). https://doi.org/10.1080/09585192.2018 .1424017

[16] Kim, M., Beehr, T. A., \& Prewett, M. S. (2018). Employee Responses to empowering leadership : A Meta-
Analysis. Journal of Leadership and Organizational Studies, 25(3). https://doi.org/10.1177/154805181775 0538

[17] Kundu, S. C., Kumar, S., \& Gahlawat, N. (2019). empowering leadership and job performance: mediating role of psychological empowerment.

Management Research Review, 42(5). https://doi.org/10.1108/MRR-04-20180183

[18] Lee, S., Cheong, M., Kim, M., \& Yun, S. (2017). Never Too Much? The Curvilinear Relationship Between empowering leadership and Task Performance. Group and Organization Management, 42(1). https://doi.org/10.1177/105960111664 6474

[19] Mangkunegara, A. P. (2012). Evaluasi Kinerja SDM (Cetakan Keenam). In PT. Refika Aditama.

[20] Pankajakshan, V. (2011). Organisational Citizenship- Engaging Employees towards Superior Performance. Aweshkar Research Journal, 12(2).

[21] Ringle, C. M., Wende, S., \& Will, S. (2005). SmartPLS 2.0 (M3) Beta. Hamburg.

[22] Robbins, S., \& Judge, T. (2009). Organizational Behaviour: Concepts, Controversies, Applications. In Development.

[23] Sarwat, N., Hayat, K., Qureshi, J. A., Ali, M., Nosheen, S., Khansa, H., Javeria Ashfaq, Q., \& Mehvish, A. (2011). Impact of strategic leadership on organizational performance, in the context of job satisfaction and organizational commitment, evidence from educational institutions of Pakistan. Interdisciplinary Journal of Contemporary Research In Business.

[24] Sönmez Çakir, F., \& Adigüzel, Z. (2020). Evaluation of empowering 


\section{EKOMBIS Sains}

leadership and Knowledge Sharing on Organization and Organization Employees. Optimum Journal of Economics and Management Sciences, $7(2)$.

[25] Sugiyono. (2018). Metode Penelitian Kuantitatif,Kualitatif dan R\&D. In $\mathrm{Ke}$ 26.

[26] Tabara, R. (2018). MODEL PENINGKATAN KINERJA SUMBER DAYA MANUSIA BERBASIS KOMITMEN NORMATIF MELALUI KEPEMIMPINAN DAN TRUST (Studi Pada Guru SLTP Distrik ' $X$ ' Provinsi Papua Barat). SENTRALISASI. https://doi.org/10.33506/sl.v7i2.152

[27] Tian, G., \& Zhang, Z. (2020). Linking empowering leadership to employee innovation: The mediating role of work engagement. Social Behavior and Personality, 48(10). https://doi.org/10.2224/SBP.9320

[28] van Assen, M. F. (2020). empowering leadership and contextual ambidexterity - The mediating role of committed leadership for continuous improvement. European Management Journal, 38(3). https://doi.org/10.1016/j.emj.2019.12. 002

[29] van Knippenberg, D., Giessner, S. R., Sleebos, E., \& van Ginkel, W. P. (2021). A motivated information processing perspective on the antecedents of empowering leadership . Journal of Applied Social Psychology, 51(2). https://doi.org/10.1111/jasp.12718

[30] Vu, H. M. (2020). Employee empowerment and empowering leadership : A literature review. Technium: Romanian Journal of Applied Sciences and Technology, 2(7).

https://doi.org/10.47577/technium.v2i7
.1653

[31] Waris, A. P. M. dan A. (2015). Effect of Training, Competence and Discipline on Employee Performance in Company (Case Study in PT. Asuransi Bangun Askrida). Procedia Social and Behavioral Sciences. https://doi.org/10.1016/j.sbspro.2015.1 1.165

[32] Webber, S. S., O’Neill, R. M., \& Dossinger, K. (2020). The empowering leadership Project. Journal of Management Education, 44(3). https://doi.org/10.1177/105256291988 4717

[33] Widianto, S. (2021). empowering leadership to performance excellence: The role of knowledge sharing and self-efficacy. International Journal of Business Excellence, 23(3). https://doi.org/10.1504/IJBEX.2021.11 3701 